\title{
Immunohistocytochemical and Immunofluorescent Localization of Catecholamine-Synthesizing Enzymes in the Carotid Body of the Bat and Dog
}

\author{
Nobuyuki Karasawa, Yukari Kondo and Ikuko NAGATSU \\ Department of Anatomy (Prof. I. NAGAtsu), Fujita-Gakuen University School of Medicine, Aichi, Japan
}

Received January 16,1982

\begin{abstract}
Summary. By the immunoenzymatic PAP (peroxidase antiperoxidase) technique and immunofluorescent methods, the localization of a catecholamine-synthesizing enzyme, tyrosine hydroxylase $(\mathrm{TH})$, in dopaminergic chief cells was elucidated in the dog and bat carotid bodies. Two types of cells were identified by PAP electron microscopy; TH-positive and TH-negative cells. The TH-positive reaction was observed both in the granules (about 170 and $300 \mathrm{~nm}$ in diameter) and in the ground substance, but not in the nucleus. Dopamine- $\beta$ hydroxylase (DBH) reaction was negative in both cells. These findings may strongly suggest the presence of tyrosine hydroxylase not only in the cytoplasmic matrix but also in the granules in the dopaminergic cells of the carotid body.
\end{abstract}

Lever and Boyd (1957) first described light and dark cells in the rabbit carotid body by electron microscopy. GaRner and Duncan (1958) confirmed the two types of cells in the cat and rabbit carotid bodies based on cell size, cytoplasmic density, and number of processes. Biscoe and Stenbens (1966) classified the chief cells as type I cells and the auxilliary cells as type II cells in the cat and rabbit carotid bodies. Снiоcchio et al. (1967), on the other hand, divided the chief cells into three types by histochemical methods. Morita et al. (1969), based on the size of granular vesicles in the cells, and Böck (1980b), based on argentaffin reaction, classified them into 4 types.

Although catecholamine was shown by histofluorescence in the cells of carotid body (Niemi and Ojala, 1964; Kobayashi, 1971a, b), Hellström and Koslow (1975), Zapata (1975), Docherty and McQueen (1978) and Matsumoto et al. (1980) identified the cathecholamine as dopamine by physiological and pharmacological methods. PEARSE and PolaK (1974) proposed the presence of a peptide named glomin, LundBerg et al. (1979) found enkephaline-like peptide, and Böck (1980a) identified adenine-like nucleotide. Though the carotid body is a chemoreceptor in reaction to the respiratory reflex, it is not yet clear whether the chief cells serve as chemoreceptors as proposed by Hess and Zapata (1972) and Kobayashi (1971b), or the other elements do as proposed by Mills and JöBsis (1972). Concerning these problems, immunohistocytochemical methods are undoubtedly useful for identification of the catecholamines in the cells. In addition, we compared the carotid bodies of the bat and dog with those of usual laboratory animals. 


\section{MATERIALS AND METHODS}

Bats (Pisistrellus abramus, 6-8g body weight) and dogs (Canis familiaris, $1.6 \mathrm{~kg}$ body weight) were anesthetized with ethyl ether, perfused through the heart with Zamboni's fixative containing $0.05 \%$ glutaraldehyde, and small blocks of the materials were postfixed overnight (about $18 \mathrm{hrs}$ ) at $4 . \mathrm{C}$ in the same solution, with the exception of glutaraldehyde. The immunofluorescence method was carried out as described by NAGATsu et al. (1974, 1977). After being washed with phosphate buffered saline (PBS), the tissue was embedded in polyethylene glycol (M.W. 1,000, Wako) and sectioned on a rotary microtome in a cold room as described previously (NAGATSU et al., 1979). Light and electron microscopic observation was carried out after three immunochemical staining: 1) with a specific antiserum for $\mathrm{TH}$ or $\mathrm{DBH}$ from the bovine adrenal medulla, 2) with goat anti-rabbit immunoglobulin G (Miles Lab.), and 3) with PAP complex (STERnBerGer and MEYER). The final treatment was carried out for 3-10 min in a mixture of $0.04 \%$ 3,3'-diaminobenzidine (Sigma Chemical Co.) and $0.03 \%$ hydrogen peroxide at final concentrations. The final specimens were prepared by dehydration and mounting for light microscopic observation, and by post-fixation in $2 \%$ osmium tetroxide and embedding in Epon 812 for electron microscopy. Ultrathin sections by LKB-8800 Ultratome were observed with a JEM-100 CX electron microscope without counterstaining with uranium and lead.

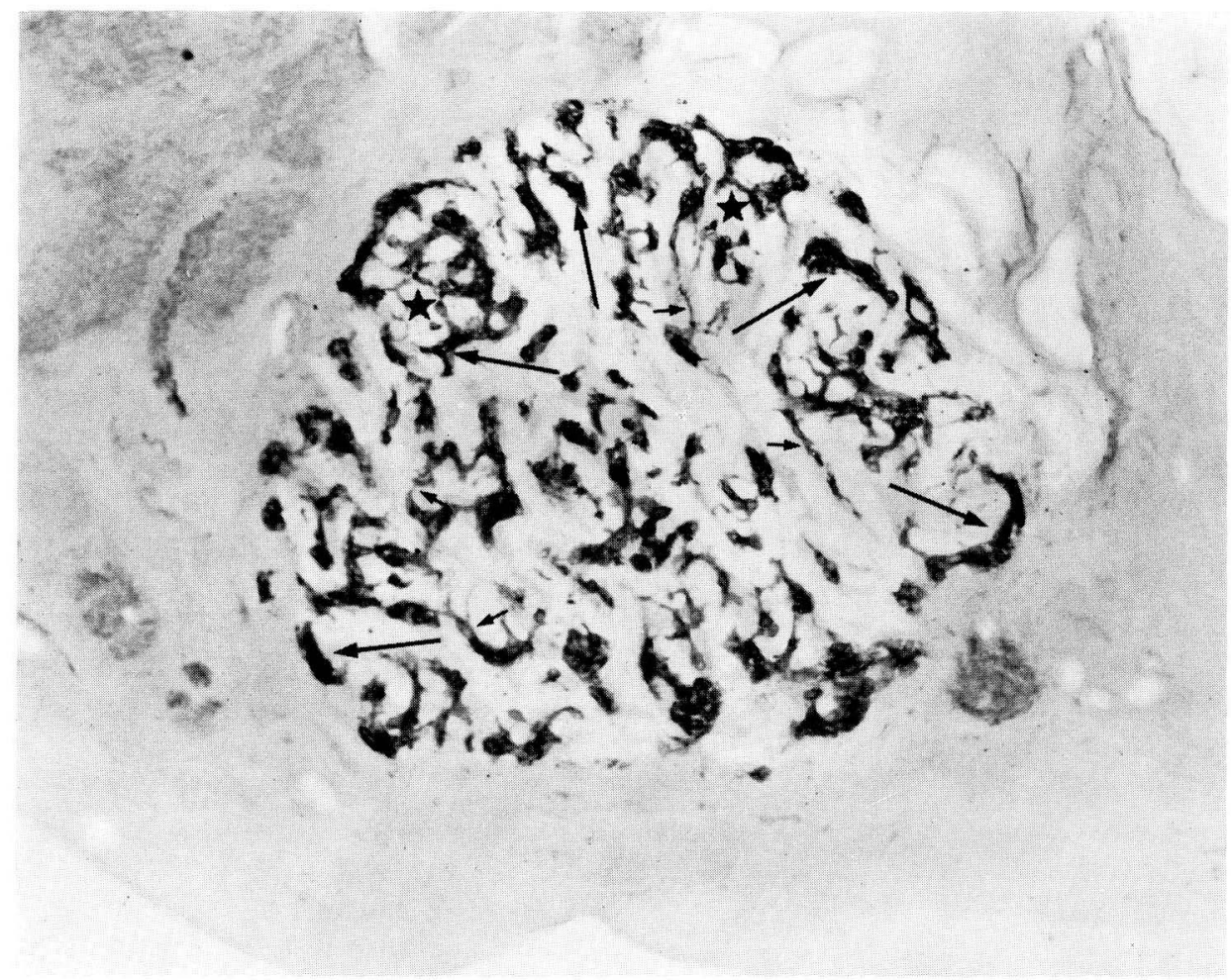

Fig. 1. An immunohistochemical photomicrograph of a bat carotid body in a $6 \mu \mathrm{m}$ thickness. TH-positive cell clusters are shown by long arrows, and TH-positive cell processes are indicated by short arrows. Capillary spaces are shown by little stars. $\quad \times 150$ 


\section{OBSERVATIONS}

The bat carotid body was located at the turning point of the external and internal carotid arteries as a circular form. By light microscopy using the PAP method (Fig. 1, TH-reaction), the carotid body appeared as a cluster of many chief cells surrounding capillaries. In the majority, TH was localized in the body and processes of the cells. By immunoelectron microscopy, oval chief cells and processes were identified to be THpositive. By the PAP method, a TH-positive reaction was also observed in the ground substance of the cytoplasm and in the two types of granular vesicles (the large granular vesicles with a diameter of about $300 \mathrm{~nm}$ indicated by a thick arrow in Fig. 2; the small granular vesicles with a diameter of about $170 \mathrm{~nm}$ indicated by an arrow head in Fig. 2). No reaction was observed in the mitochondria, nucleus and nuclear membrane.

Another type of chief cells showed a TH-negative reaction and loosely contacted the TH-positive cells; their granular vesicles (about $170 \mathrm{~nm}$ in diameter) were not so dense as those in the TH-positive cells. The fibrocytes (mesenchymal cells) surrounding the chief cells were TH-negative.

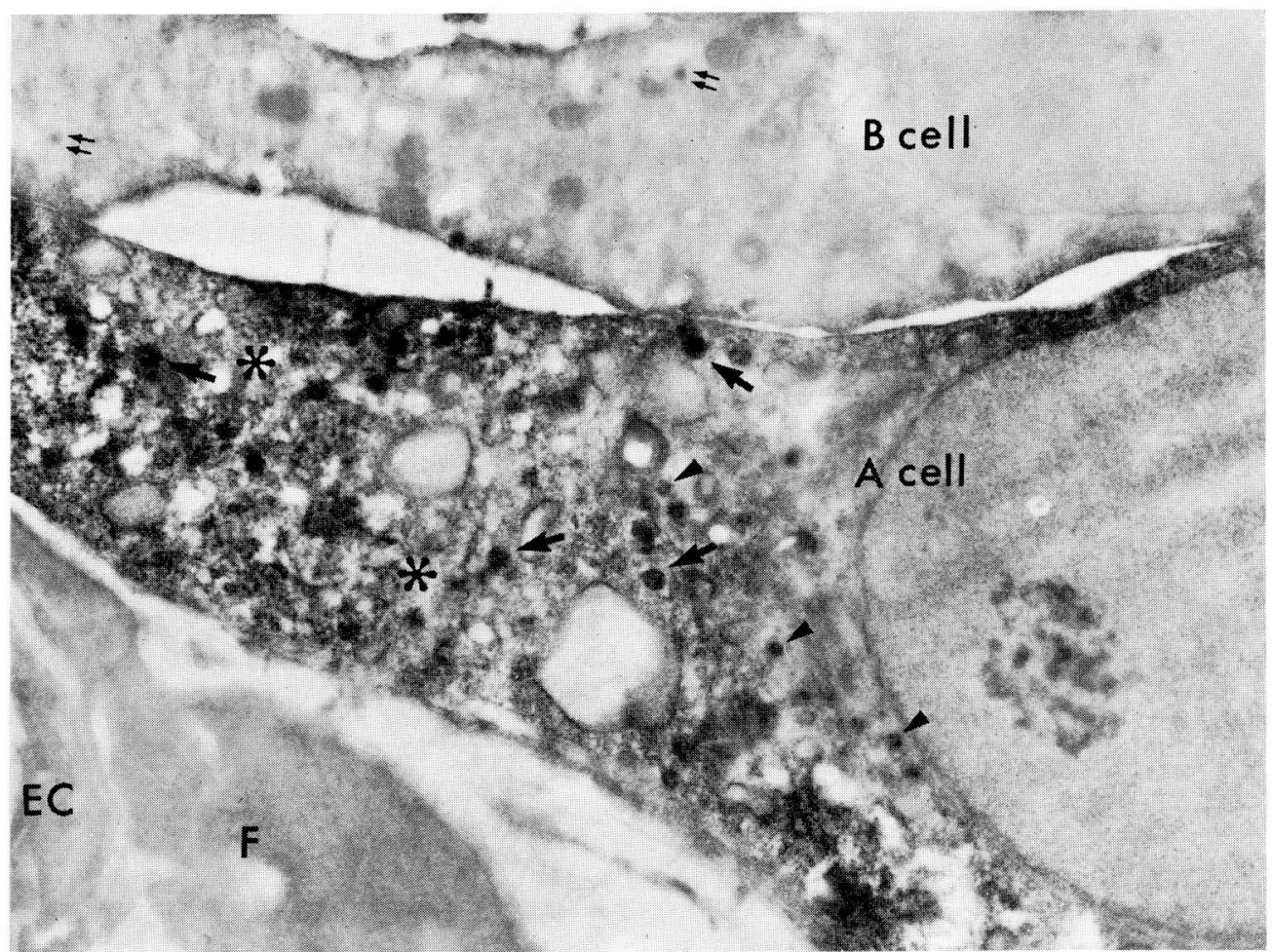

Fig. 2. An immunoelectronmicrograph of a bat carotid body by TH reaction. The A cell is THpositive, and the B cell is TH-negative. The cytoplasm (*) and granular vesicles (thick arrow and arrow head) of the A cell show a TH-positive reaction, and nucleus is TH-negative. The size of the TH-positive large granular vesicles (thick arrow) is about $300 \mathrm{~nm}$ in diameter, and that of the small TH-positive granular vesicles (arrow head) is about $170 \mathrm{~nm}$ in diameter. The cytoplasm, granular vesicles and nucleus of the B cell are TH-negative. The size of the $\mathrm{B}$ cell is about $170 \mathrm{~nm}$ in diameter (double thin arrow). There is no basement membrane between the A cell and B cell, and the A cell and B cell directly contact each other. The fibrocyte $(F)$ and an endothelial cell (EC) of a capillary are TH-negative. $\times 9,000$ 


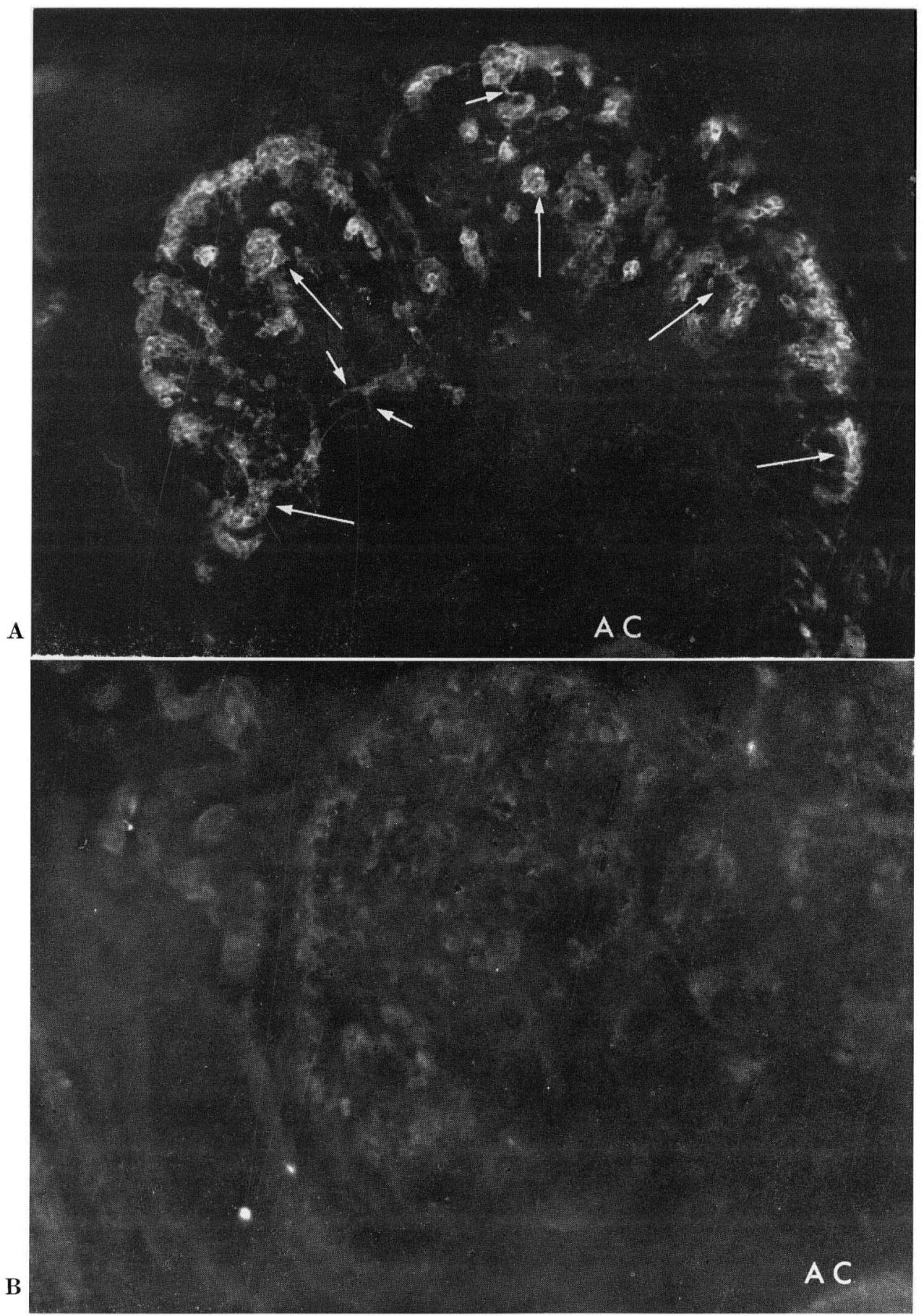

Fig. 3. Immunofluorescence photomicrographs of a dog carotid body in a $10 \mu \mathrm{m}$ thickness. A. TH-reaction. The TH-positive cell clusters are indicated by long arrows, and the TH-positive cell processes are shown by short arrows. $\times 140$. B. DBH-reaction. The DBH-specific immunofluorescence is hardly seen. $A C$ arteria carotis. $\times 140$ 
The dog carotid body was observed at the turning point of the external and internal carotid arteries as oval or circular in form, similar to that of the bat. By immunofluorescence, TH-positive cells were arranged as clusters, and their long processes were observed around the capillary wall (Fig. 3 A).

On the other hand, DBH reaction was negative both in the bat and dog carotid bodies (dog carotid body shown in Fig. $3 \mathrm{~B}$ ). These results suggest that the chief cells of bat and dog carotid bodies are dopamine cells.

\section{DISCUSSION}

Through high performance liquid chromatography (HANSEN and CHRISTIE, 1981), catecholamines in the rat carotid body were found to be about $53 \%$ dopamine, $36 \%$ noradrenaline and $10 \%$ adrenaline, respectively.

By histofluorescence technique, Hess (1978) reported that all glomus cells most likely contained dopamine and that the noradrenaline biochemically present in the carotid body may be localized in the autonomic nerve fibers ramifying in the carotid body and in the sporadic ganglion cells found in and adjacent to the carotid body, but not in the glomus cells. Bolme et al. (1977) confirmed the above results by immunohistochemical study using catecholamine-synthesizing enzymes in the rat carotid body.

In the present study, two kinds of chief cells with TH-positive or TH-negative reaction were found; the former contain two types of granular vesicles $170 \mathrm{~nm}$ and $300 \mathrm{~nm}$ in diameter, and the latter contain granular vesicles $170 \mathrm{~nm}$ in diameter.

The chief cells of the bat and dog carotid bodies were found to be mostly dopaminecontaining cells, but we also found non-catecholaminergic glomus cells by TH-immunoelectron microscopy. It can be suggested that they are possibly serotonin-containing glomus cells.

LEVER and BOYD (1957) first reported osmiophilic granules of 50-150 nm in diameter in the dark cells of the rabbit, and Morita et al. (1969) tried to classify them into 4 types: 170 and $400 \mathrm{~nm}$ in diameter with noradrenaline, $130.1 \pm 3.5 \mathrm{~nm}$ in diameter with dopamine, $93 \pm 2.4 \mathrm{~nm}$ in diameter with serotonin, and $120 \pm 30 \mathrm{~nm}$ in diameter with adrenaline. Estimation of the transmitters in the granular vesicles by their sizes, shapes or densities, however, lacks specificity and is not convincing.

NAGATSU et al. (1979) observed TH- and DBH-positive granules of 200-250 nm in diameter in the rat adrenal medulla based on the immunocytochemical technique. In the rat substantia nigra, PICKEL et al. (1976) found TH-positive granules of 60-80 nm in diameter, while KARASAwA et al. (1981) identified TH-positive granules of $90 \mathrm{~nm}$ in diameter in the hamster substantia nigra and also in the bat Meissner's plexus. Palkovits et al. (1977) reported the presence of dopamine granules $(60-100 \mathrm{~nm}$ in diameter) in the inner layer of the rat median eminence by degeneration studies with lesion or 6-OH-dopamine injection in the substantia nigra.

These findings suggest that TH-positive granules are smaller in size in the nervous tissues than those of the paraneuron system such as in the adrenal medulla and carotid body. It seems reasonable to postulate that the TH-positive small granules of $170 \mathrm{~nm}$ in diameter demonstrated in this study may correspond to dopamine-containing granules, and TH-positive large granules $(300 \mathrm{~nm})$ may contain some other peptides. THnegative granules $170 \mathrm{~nm}$ in diameter found in this study may also contain peptides or unknown chemical messengers other than catecholamines. 


\section{REFERENCES}

Biscoe, T. J. and W. E. Stehbens : Ultrastructure of the carotid body. J. Cell Biol. 30: 563-578 (1966).

Böck, P.: Adenine nucleotides in the carotid body. Cell Tiss. Res. 206: 279-290 (1980a).

: Noradrenaline and acidic protein(s) in four types of cat carotid body chief cells. Arch. histol. jap. 43: 23-34 (1980b).

Bolme, P., K. Fuxe, T. Hökfelt and M. Goldstein : Studies on the role of dopamine in cardiovascular and respiratory control: central versus peripheral mechanisms. Adv. biochem. Psychopharmacol. 16: 281-290 (1977).

Chiocchio, S. R., A. M. Biscardi and J. H. Tramezzani : 5-Hydroxytryptamine in the carotid body of the cat. Science 158: 790-791 (1967).

Docherty, R. J. and D. S. McQueen : Inhibitory action of dopamine on cat carotid chemoreceptors. J. Physiol. 279: 425-436 (1978).

Garner, C. M. and D. Duncan : Observations on the fine structure of the carotid body. Anat. Rec. 130: 691-709 (1958).

Hansen, J. T. and D. S. Christie : Rat carotid body catecholamines determined by high performance liquid chromatography with electrochemical detection. Life Sci. 24: 1791-1795 (1981).

Hess, A. and P. Zapata: Innervation of the cat carotid body: normal and experimental studies. Fed. Proc. 31: 1365-1382 (1972).

Hellström, S. and S. H. Koslow : Biogenic amines in carotid body of adult and infant rats-a gas chromatographic-mass spectrometric assay. Acta physiol. scand. 93: 540-547 (1975).

Karasawa, N., Y. Kondo, T. Sato, H. Niimi and I. Nagatsu: Immunohistocytochemical studies of mammalian dopaminergic cells. Acta anat. nippon. 56: 262-263 (1981).

Kobayashi, S.: Comparative cytological studies of the carotid body.1. Demonstration of monoaminestoring cells by correlated chromaffin reaction and fluorescence histochemistry. Arch. histol. jap. 33: 313-339 (1971a).

-: Comparative cytological studies of the carotid body. 2. Ultrastructure of the synapses on the chief cell. Arch. histol. jap. 33: 397-420 (1971b).

Lever, J. D and J. D. Boyd: Osmiophile granules in the glomus cells of the rabbit carotid body. Nature 179: 1082-1083 (1957).

Lundberg, J. M., T. Hökfelt, J. Fahrenkrug, G. Nilsson and L. Terenius : Peptides in the cat carotid body (glomus caroticum): VIP-, enkephalin-, and substance P-like immunoreactivity. Acta physiol. scand. 107: 279-281 (1979).

Matsumoto, S., T. Nagao, A. Ibi and T. Nakajima: Effects of carotid body chemoreceptor stimulation by dopamine on ventilation. Arch. int. Pharmacodyn. 245: 145-155 (1980).

Mills, E. and F. Jöbsis : Mitochondrial respiratory chain of carotid body and chemoreceptor response to changes in oxygen tension. J. Neurophysiol. 35: 405-428 (1972).

Morita, E., S. R. Chiocchio and J. H. Tramezzani : Four types of main cells in the carotid body of the cat. J. Ultrastr. Res. 28: 399-410 (1969).

Nagatsu, I., B. K. Hartman and S. Udenfriend: The anatomical characteristics of dopamine- $\beta$ hydroxylase accumulation in ligated sciatic nerve. J. Histochem. Cytochem. 22: 1010-1018 (1974).

Nagatsu, I., Y. Kondo, S. Inagaki., N. Karasawa, T. Kato and T. Nagatsu : Immunofluorescent studies on tyrosine hydroxylase: application for its axoplasmic transport. Acta histochem. cytochem. 10: 494-499 (1977).

Nagatsu, I., N. Karasawa, Y. Kondo and S. Inagaki : Immunocytochemical localization of tyrosine hydroxylase, dopamine- $\beta$-hydroxylase and phenylethanolamine- $\mathrm{N}$-methyltransferase in the adrenal glands of the frog and rat by a peroxidase anti-peroxidase method.: Histochemistry 64: 131-144 (1979).

Niemi, M. and K. Ojala : Cytochemical demonstration of catecholamines in the human carotid body. Nature 203: 539-540 (1964). 
Palkovits, M., Cs. Leranth, L. Zaborszky and M. J. Brownstein : Electron microscopic evidence of direct neuronal connections from the lower brain stem to the median eminence. Brain Res. 136: 339-344 (1977).

Pearse, A. G. E. and J. M. Polak: Endocrine tumours of neural crest origin: Neurolophomas, apudomas and the APUD concept. Med. Biol. 52: 3-18 (1974).

Pickel, V. M., T. H. Joh and D. J. Reis : Monoamine-synthesizing enzymes in central dopaminergic, noradrenergic and serotonergic neurons. Immunocytochemical localization by light and electron microscopy. J. Histochem. Cytochem. 24: 792-806 (1976).

Zapata, P.: Effects of dopamine on carotid chemo- and baroreceptors in vitro. J. Physiol. 244: 235-251 (1975).

永津郁子

干470-11 豊明市沓掛町田楽ヶ窪 1-98

名古屋保健衛生大学医学部

解剖学第二講座
Prof. Ikuko Nagatsu

Department of the 2nd Anatomy

Fujita-Gakuen University School of Medicine

Toyoake, Aichi, 470-11 Japan 